\title{
An Indigenous Woman in the Apocalyptic City: Exploring the Multifaceted Urban Panorama in Louise Erdrich's Future Home of the Living God
}

\author{
Svitlana Kot \\ PhD student, English Philology Department, Petro Mohyla Black Sea National University, \\ Mykolaiv, Ukraine. ORCID id https://orcid.org/oooo-0oo2-1462-1276 \\ Email:svitlana.kot@chmnu.edu.ua
}

\begin{abstract}
In light of rapidly spreading urbanization and the constant growth of indigenous populations living in cities, urban Indian narratives emerge as a means to battle simulations and invisibility of Native Americans in the city by demonstrating stories of resistance, survival and identity preservation. Native American literature written in the city and about the city plays an essential role in reimagining and redefining indigenous space and its representation in modern American culture. This study aims to contribute to this growing area of research by exploring urban space in novel Future Home of the Living God by Louise Erdrich, a Native American writer. Despite apocalyptic symbolism and fictional nature, this novel is both an indigenous perspective on the city space and a reflection of urban Indian experience. By employing an interdisciplinary coordinate system and combining spatial analysis with the transcultural approach, eco-feminism and Foucauldian analysis of power distribution, this study offers some critical insights into Native American vision of urban nature and future, as well as culture, gender, politics, and ecology, while also demonstrating that indigenous people are active thinkers involved in urban discourse.
\end{abstract}

Keywords: dystopia, eco-feminism, Native Americans, transculturalism, urban space.

\section{Introduction}

A number of Native and non-Native American authors and critics (Deloria, 1993; Garroutte 2003; Noodin 2014; Furlan 2017), including writer Louise Erdrich (1985) within her essay "A writer's sense of place", have shown that space in its various manifestations is crucially significant for Native Americans due to various factors, which is not only true when ancestral homelands are the focus of attention but also in present-day globalized and urbanized contexts. As Laura M. Furlan (2017) states: "Land, location, and belonging are critical themes in this era and in the literature that describes it as Indigenous peoples appear and reconfigure themselves in the urban landscape, staking claims in the city space" (p.19). Indeed, in light of rapidly spreading urbanization and a dramatic increase in the number of indigenous people who live in big cities, it is becoming extremely difficult to ignore the changing spatial paradigms. However, despite the fact that more than one-third of the Native American population lives in urban areas (Lyubymova , 2019, p. 9), they seem to stay invisible in cities; hence, the growing interest on behalf of both writers, who remap American space by depicting experiences of Native Americans living in the city, and scholars, who study urban texts and urban Indian representations.

(c) AesthetixMS 2020. This Open Access article is published under a Creative Commons Attribution Non-Commercial 4.0 International License (http://creativecommons.org/licenses/by-nc/4.o/), which permits non-commercial re-use, distribution, and reproduction in any medium, provided the original work is properly cited. For citation use the DOI. For commercial re-use, please contact editor@rupkatha.com. 
To counteract mistaken dissociations between indigenous people and urban space stemming from the colonial discourse, several studies (Forbes, 2001; Furlan, 2017) have postulated that Native Americans have always lived on the territories of cities and in spaces that represented an urban schema. Despite the European invasion destroying indigenous space in both Americas and displacing people from their original urban territories to mainly rural areas, Native concepts of urbanism should not and cannot be limited to the period of European colonization (Forbes, 2001, p.23). American cities as Laura M. Furlan (2017) claims have a long history of relations between settlers and an indigenous population (p. 12) which has configured urban spaces as active contact zone ${ }^{i}$. The most drastic increase in the number of Indians in American cities, however, is connected with the relocation movement in 1950, which Mishuana Goeman ( 2013) refers to as the "1950s construction of the urban Native" (p.7).

Historically, the body of literature investigating the factors associated with Indians living in the city has focused on complex social and physiological problems of Native Americans in the process of integration into the city space. Traditionally, it has been postulated that relocation aimed at removing Native Americans from their communities and produced weakened tribalism through assimilation. However, relocation never equated with complete assimilation. Despite declaring multiple problems with urban life, including a lack of support with adaptation, low quality of available jobs and confusion about where to seek out essential social services (Philp, 1985, p. 189), Native Americans were not only able to adjust but also integrate into their newfound city spaces. According to a Choctaw scholar, Karina L. Walters (1999), in order to counteract the negative colonizing process and maintain positive identity attitudes, urban Indians are able to transform native cultures, integrating them into new spaces and "taking the best of both worlds" by internalization of positive self-view and externalization of negative dominant culture preconceptions (p.163). Therefore recent studies of indigenous urban experience have shifted the perspective on urban Indians while trying to dismantle the dominant narrative about indigenous people who "were not adaptable, assimilable, and didn't belong in the city".

Over the past several decades, there has been an increasing number of studies on the urban representation of indigenous experience and stories of cultural preservation in city spaces from a Native perspective. A great deal of research into this aspect, including those conducted by Laura M.Furlan (2017), Mishuana Goeman (2013), Susan Lobo \& Kurt Peters (2001), and Carol Miller (2001), among many others, have focused on the literature written by modern Native American writers. One of the most recent and systematic studies on this subject mentioned above by Laura M.Furlan (2017), Indigenous Cities: Urban Indian Fiction and the Histories of Relocation, introduces a new way to examine Native American urban experience. In her book, Furlan defines Indian urban writing as texts written in a city and about a city, as a new reality of indigenous experience and argues that such texts articulate a radical shift of Indian identities because they give a new image of "indigenous space." Furlan argues that urban Indian writing since the 1950s is about cultural survival and states: "Urban Indians narratives are not solely about despair and dislocation; they imagine a cultural past identified with ancestral lands and/or a reservation and a present that require the making and remaking of Native bonds and communities. Together, these authors represent a new direction in American Indian writing" (p.3). This view is further supported by scholar Carol Miller (2001) in her paper "Telling the Indian Urban. Representation in American Indian Fiction", who claims that while urban spaces in early Native writing manifested negatively through ideas of cultural alienation; degradation; physical threats of danger; separation; disillusion; and dissolution; later post-relocation urban Indian writing ultimately surmounts invisibility and victimization while creating an idea of urban Indian-ness that articulates cultural vitality (p.29-31). Thus urban Indian writing not only puts forth the idea of the survival of Native 
Americans in the city and redefinition of Indian identity in spaces outside the reservation but also broadens and remaps symbolic and real landscapes of Indian country while inscribing Native American experiences in urban narratives.

Such a substantial shift in Native American writing is brought about by urban realities of indigenous experience. Not only cityscape comes in the foreground but also expends various horizons. In general terms, a big city opens a much broader global panorama of the social, political, cultural, industrial processes which are taking place in the world. The intersection of the global urbanistic panorama with indigenous sensitivities forms a much broader perspective. Hence urban Indian writing focuses not only on Indian experience but also complex environmental, social, and political issues adopting a unique perspective of indigenous wisdom and cutting-edge horizons of the urban experiences.

Louise Erdrich, as a Native American author amply demonstrates the shifts occurred in Native American writing. Although Louise Erdrich has been a metropolis dweller for a long time, she, as an author, has rarely chosen urban settings for her novels, opting instead for small towns or reservation spaces. A fictional reservation in North Dakota was long the critical center of Erdrich's books. Scarcely, the author discusses Minneapolis-Saint Paul in Four souls and The Antelope-wife. Consonant with former experiences of reservation Indians Four Souls depicts the city as gloomy, mechanical, and alien to a Native American protagonist.

Far across the fields she could hear the city rumbling as she came near, breathing in and out like a great sleeping animal.<...>The movement of mechanical, random things sickened her. The buildings upon buildings piled together shocked her eyes. The strange lack of plant growth confused her. The people stared through her as though she were invisible ... (Erdrich, 2005, The Roads, para. 7)

In Four Souls the author represents the city, Gakaabikaang, as a stratum over the Indian land juxtaposing the two and so she does in The Antelope-wife. However, several studies (Gamber, 2012, p.111-113; Noodin, 2014, p.45) have demonstrated that the image of the city in The Antelope wife starts to shows some ambivalence. On the one hand, the city keeps negative connotations, but on the other, it redefines the image of Native Americans as people who belong exclusively to reservation spaces and shows that they are able to adapt, expand new horizons and accept city spaces as a reality of modern life.

Although not breaking totally with the reservation space in her most recent novel, Future home of the living God, published in 2017, Erdrich makes a cityscape the main arena of actions. Future home of the living God is a novel that fits into a genre of dystopia as it shows the near future on the verge of an ecological apocalypse. Written as a journal entry from the protagonist, Cedar Hawk Songmaker, to her unborn child, the novel pictures a world evolving backward while also dominated by an oppressive regime. The protagonist's attempts to find a safe place to give birth make her escape, hide, and wander in-between various loci, which seem to resemble a search for home fairly characteristic of Native American literature. While, as mentioned above, some research has been carried out based on Erdrich's other novels as material to explore the Native perspective of city space, no single study exists which focuses on spatiality in her latest novel. As Future home of the living God is one of Erdrich's first texts where the city comes on the foreground, this essay aims to explore the distinguishing features of urban spatial configuration in the novel.

Characterization of urban space is important for the increased understanding of the role a city plays today in lives of indigenous peoples and the way indigenous peoples as urban dwellers 
estimate nature, challenges, and prospects of a modern city. As a Chippewa scholar Danika MedakSaltzman (2017) claims:

[E]ven though Native communities, our governance structures, the complexities of our social engagement, and the variety of our narrative traditions have always incorporated elements of futurity, prophecy, and responsibility-rooted strategies for bringing forth better futures, mainstream narratives represent a profound and pervasive inability to portray Native peoples and our continued existence in the present, let alone to project us forward into any potential futures. (p.139)

In this study, the city is approached from various sides: first as a space of belonging of an indigenous person and then as a critical site of the apocalyptic space which is both a victim to an anthropogenic ecological catastrophe and totalitarian regime. This paper has been divided into three parts. The first part looks at how the cityscape is pictured and in what way the environmental crisis marks the depiction. The second part goes more in-depth into investigating the city as a place of belonging for a Native American protagonist. The third part explores how the cityscape is structured and modified by power mechanisms.

The methodological approach taken in this study is a mixed methodology based on transcultural, feminist, ecocritical, Foucauldian approaches. While urban Indian narratives transpose the coordinate system into the urban space form a new standpoint from which to articulate indigenous experience and identity, a transcultural approach should be adopted. Standing in as a form of cultural representation, urban Indian texts confront the prevailing stereotypical representations of indigenous populations and demonstrate that the spatial reality, as well as identities and life experiences of Native Americans, are multifaceted and diverse. The metropolis which acts as a massive conglomeration, complete with a highly dense and considerably diverse population presumes regular close cultural contacts. Significantly enhanced by the impact of globalization, which is especially evident in urban spaces, cultural collisions affect individuals who nevertheless have relative freedom to choose from a variety of cultural components. Transculturation for Native Americans in urban realities implies blurred distinctions between various indigenous and non-indigenous cultures. Therefore, the transcultural perspective is an effective way to explore the way the protagonist of an indigenous background fits into a big city.

The above-mentioned nature of the metropolis, namely dense population, the far-reaching impact of globalization, industrial character, the institutional structure makes the city extremely susceptible to environmental crises and systematic control. As noted by Diane Wolfe Levy (1978) in her seminal analysis of European urban literature, city/country dichotomy often appears in the form of polarized metaphors between good and evil. Levy points out that urban decadence often contrasts with "a nostalgically pastoral innocence" (p.66). Native American sensitivity would offer a more profound insight here, as according to Kyle P. Whyte (2018), a Potawatomi scholar and activist, indigenous people live in the situation of an ongoing ecological crisis. The scholar claims that what might be seen as imaginaries of apocalyptic future has happened to indigenous people as a result of different forms of colonialism: destruction of ecosystems, extinction of economically and culturally significant species or loss of access to them due to relocation, cultural dissolution (p.226). Therefore an ecocritical approach is adopted to provide rounded, detailed illustrations of the city as a sight of ecological collapse, while a Foucauldian analysis of space construction combined with feminist criticism is chosen to obtain further in-depth information on the city as a sight of gender oppression. All of this combined with the indigenous perspective is an important opportunity to advance the understanding of both the urban space and urban indigenous experiences. 


\section{A "Before" Disaster Photograph: Environmental Horizons of the Urban Space in Future Home}

The following part of this paper moves on to describe in greater detail the portrayal of the cityscape as seen through the eyes and described in the diary of the protagonist, a mix-blood indigenous pregnant woman adopted to and living her life in the city of Minneapolis. The passage that provides initial insight into Minneapolis city in the novel describes it in a surprisingly positive manner. "Surprisingly" is used here not to point out the common misconception mentioned previously concerning city life as a site of alienation and despair for people of indigenous background. An attractive description of the urban space would seem rather a-typical for many literary traditions, because of the tendency to depict the city as predominantly gloomy or monstrous, especially in comparison with rural spaces. It is specifically true for dystopian novels, in their comparison with utopia, as a dystopian city could rarely be thought of as a topos with no negative connotations. Nevertheless, Future Home of the Living God transcends traditional dichotomous configurations fluctuating between positive imagery and apocalyptic spatial symbolism.

The initial observation indicates that the image of the city in the novel carries fairly positive connotations evidenced from its favorable portrayal, which gradually begins to clash with the growing menace of an ecological apocalypse marking the depiction. At the beginning of the novel, the protagonist, who is also the narrator, depicts a highly positive image with a welcoming atmosphere, happy people, and a usual-not hectic-pace of life. Cedar recollects, "Driving to my house, I saw that the streets were full of the usual number of normal, purposed, smiling, and gregarious Minnesotans, people talking at the bus stops. People carrying their shopping bags and backpacks, walking at an appropriate rate of speed, not looking either shaken or scared" (Erdrich,

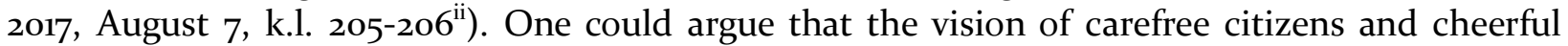
urban space within a dystopian novel -creates deception, even anxiety, and specific kind of "the calm before the storm." However, even when Erdrich's protagonist is imprisoned within the maternity ward by a newly established autocratic regime, images of the urban space partially preserve positive connotations. "A gorgeous view of the eastern side of the city and the Mississippi River" is what Cedar sees from her window, which further adds to the established narrative of a "surprisingly" soothing comfort of the city space."I watch the sunrise each morning, lighting the steel beams of the bridge, touching the brick walls with hands of fire, passing bars of radiance along the gravel and the asphalt toppings on the roofs below. As the warmth advances, mist lazily floats from the still, green leaves of far-off bushes and giant trees, and swirls in the scarlet and green maples, dogwood, viburnum" (Erdrich, 2017, September 27, k.l. 1973). Complete with sun warmth and radiance, the city atmosphere Erdrich develops does not appear to be intimidating or alarming. Random people going back and forth across the University of Minnesota Bridge seem to live a life un-bothered by the approaching end of the world. The flow of time in the city is invisible yet abrupt. Imprisoned by the still time of living in a hospital ward, Cedar is not able to feel outside time, the flow of which is only noted through seasonal changes in the cityscape. The trees which are changing colors from green to gold and then to "russet, hot yellow, pink, orange, and [finally] deep bloody red" bare symbolic significance brings about the feeling of an upcoming tragedy. Notwithstanding the idea of a catastrophe in the air, the positive descriptions of the city infer the protagonist's emotional attachment to the topos.

Although the urban space in the novel seemingly assumes a secular character, it reflects the indigenous idea of spirituality, which is genuinely environmental. The church, which the 
protagonist attends, is far from a transcendentally metaphysical locus both in form and content. It is described as "a humble place". Temples and sacred sites are commonly assumed to represent the belief system of the society through their spatial structure. Thus, unlike the imposing Catholic cathedrals which tower above the surrounding space in an attempt to reach God, or lavish modern Protestant churches which reflect the spirit of the consumerist epoch, the uniformly neutral church that Erdrich depicts in her novel illuminates not God but instead the human beings and their relationships as the primary value. It is made emphatic that the church is not related to deities and rather than possessing the name of a saint; instead, the church was named after "Holy Incarnation" and dedicated to the destitute people: "the cast-asides, the no-goods, the impossible, the toxic and contaminated." As the protagonist points out, it is not the church of the saved, but a church of the lost. The idea behind the name is to glorify human nature as omnipotent and manifest that the conception of divinity as a universal life force is immanently present in every individual. The protagonist articulates her feelings by quoting Thomas Merton's Raids on the Unspeakable:

Into this world, this demented inn, in which there is absolutely no room for Him at all, Christ has come uninvited. But because He cannot be at home in it, because He is out of place in it, and yet He must be in it, His place is with those who do not belong, who are rejected by power because they are regarded as weak, those who are discredited, who are denied the status of persons, tortured, exterminated. With those for whom there is no room, Christ is present in this world. (Erdrich, 2017, October 15, k.1. 2426)

Represented by a catholic deity, the spirituality in the novel is infused with an indigenous perspective. It pays homage to the divine in a living person who is not separated but both physically and spiritually present in the real world. Thus a human being is the very living God from the title of the novel who needs an ecologically stable planet now and in the future as the home.

The symbolism of light in the novel reveals the multifaceted nature of the urban space. At several narrative points, the lack of light signifies the end of healthy life and transforms the cityscape into a site soon facing disaster. The inner city's lower-working class neighborhoods, dotted with rundown houses, along with tiny strips of lawns and fences, look calm and neat but darkness reveals bonfires, gunfire, cries, and shouts, and ultimately illuminates the whole wounded topography of the space as on the verge of collapse. Cedar and the father of her child try to escape the city:

The street is without electricity. The whole neighborhood has lost power. Which is not unusual, and yet it seems that something much worse has happened, for my graceful childhood street has the stillness of an ancient dream, the muted perfection of a "before" disaster photograph. I try to shake off this disquiet. But all the way back along the calm, empty South Minneapolis streets, I feel that, instead of the past, it is the future that haunts us now" (Erdrich, 2017, August 11, k.l. 1023).

Cedar's nostalgic vision of the city as an impeccable and moving topos suggests that it is not the city itself which expels its people. The city thus should be viewed as a victim of the ecological disaster together with its inhabitants. It is apparent that Erdrich does not blame the city nor the world by assigning the spatiality with negative connotations. Instead, in her peculiar manner, she infers how inhabitants might change the Earth, its topographic and ecological patterns as well as their biological essence by not thinking of sustainability. 


\section{A "Real Ojibwe Person" vs. "a Theoretical Native" in the City: Transcultural Cityscape in Future Home}

As was mentioned in the introduction of the paper, the city has always been stereotypically perceived as a topos alien to indigenous people where assimilation and breakdown from tribal cultural heritage are inescapable. This section attempts to answer the question of roots, belonging and Indian identity in the urban space. As the analysis demonstrates, Future Home of the Living God perpetuates the idea that it is a lack of genuine indigenous representations in the city which reinforce common fallacies both in mass culture and within indigenous peoples themselves. Even though throughout the text the adoptive parents of the protagonist respect and thus attempt to cherish and uphold the traditions of her Native heritage, the representatives of a white background contribute their understanding of what constitutes Native culture;

Bubbles of public speculation float over us. During one of Sera's many self-invented ceremonies, which she put together from her eclectic readings on indigenous culture and Rudolf Steiner, we placed sacred tobacco all around our house and then smudged white candles with sage and stuck them in the ground and lighted them. We ate bread, walnut pâté. I drank ginger beer, and my parents drank wine. We curled up on blankets in the grass and sang peace-march songs until we fell asleep. It is one of the best memories of my life. (Erdrich, 2017, August 11, k.l. 858)

The unique fusion of indigenous and Euro-American cultural elements transforms the family's modern, comfortable dwelling in a respectable neighborhood of Minneapolis and their family life into a contact zone. Although inspired by inauthentic sources, the made-up Native ceremonies and rites aimed at maintaining their adoptive daughter's indigenous cultural identity were still able to lay the foundation for the latter concurrently modifying the paternal home into a transcultural site while reshaping the identities of everybody involved into hybrid entities.

Spatial and spiritual separation from an authentic cultural background and community manifests itself in the paucity of indigenous cultural meanings attached to urban space that may be substituted by distorted representations absorbed from the mass culture. Erdrich seems to illustrate Gerald Vizenor's (1999) idea iii about an Indian as a simulation by choosing to depict her protagonist, Cedar, as "a theoretical Native" in the city. The cliché image of an Indian girl as one who has an intimate connection to nature is further perpetuated by Cedar's every step as she explains: "But even one-braided, even as a theoretical Native, really, I always felt special, like royalty, mentioned in the setting of reverence that attended the study of Native history or customs. My observations on birds, bugs, worms, clouds, cats and dogs, were quoted. I supposedly had a hotline to nature" (Erdrich, 2017, August 7, k.l. 52). Erdrich also articulates the scarcity of authentic indigenous representations in the city by drawing on the image of the Land O'Lakes Butter Maiden (an Indian girl depicted on a butter box) as the father of Cedar's child associates her with this image. Again, the theoretical Native emerges as the brand image of a well-known dairy company uses an indigenous woman pictured amongst a background of an idyllic scenery of lakes, pines, flowers, and grazing cows. By accentuating a salacious cliché image of "a lovely, voluptuous Native girl kneeling in a lakey landscape <...> in short dress of fringed buckskin" wearing high-heeled leather moccasins, Erdrich not only raises the question of indigenous women being appropriated, commodified, sexually objectified, and refused to be seen as contemporary and multi-dimensional, but she is also drawing upon stereotypical spatial patterns. Such kinds of representations conserve the pastoral wilderness as the primary spatial association with the indigenous population. The novel infers that similarly to the infinite-loop motif of the picture, in which the image of the Indian 
girl is repeated infinitely within itself, Indian-ness as a simulacrum without actual references in American culture continuously replicates itself.

Erdrich demonstrates that the city remains the place where Indian simulations thrive due to a lack of authentic representations while also suggesting that cultural preservation and authentic identification is achievable via communal pan-Indian ties. This phenomenon becomes evident as the protagonist's artificially constructed Indian-ness fades out from the moment she gets acquainted with a real Indian community;

I became ordinary, then. Even worse, I had no clan, no culture, no language, no relatives. Confusingly, I had no struggle. In our talking circles, I heard stories. Addictions. Suicides. I'd had no crises in my life, besides the Retro Vinyl clerk, so I invented one. I chopped off both braids, then stopped going to classes. I'd been a snowflake. Without my specialness, I melted (Erdrich, 2017, August 7, k.l. 57).

Not only is the author emphasizing a lack of authentic indigenous representations in the city, but Erdrich is also illuminating the importance of community in constructing an ethnic identity. As evidenced by the text: the pan-Indian shared heritage, historical background, cultural memory, including but not limited to traditions, believes, and collective traumas are seen as the basis for identity.

The protagonist's belonging to the urban space is beyond a doubt. In her normal life, a typical city-dweller of South Minneapolis, Cedar lives on "a forgotten dead end running right up to an unused railroad embankment" in a small bungalow, whose "backyard pours into the tangle of the forgotten railroad right-of-way, overgrown with scruffy trees." Such an industrial cityscape as a point of belonging challenges the stereotypical associations about the indigenous setting. The protagonist declares being happy there, which shows a significant positive correlation between her as an individual, her house, and the urbanistic landscape of her everyday life. Although, in actuality, a mixed-blood protagonist can be said to have several homes and live in-between two cultures and two spatial realities. Among the adoptive parental house in a nice Minneapolis neighborhood, the home of her blood family on the reservation, and her own dwelling, she gives preference to the latter. It is her home that conveys the highest level of intimacy defending her from the outside. Cedar acknowledges:

Still, this is our haven and our den, the place I can be merely the nameless being I am, a two-decade-plus collection of quirks and curiosities, the biochemical machine that examines its own mind, the searcher who believes equally in the laws of physics and the Holy Ghost, in reading my favorite theologian, Hans Küng (the one chastised by Ratzinger but loved by our present pope), and trying to live by the seven Ojibwe teachings, Truth Respect Love Bravery Generosity Wisdom Humility, which I've only read about and do not know from, say, a real Ojibwe person. (Erdrich, 2017, August 15, k.l. 1037)

The protagonist admits having a hybrid identity which stems not from binary oppositions but rather from combinations of various cultural elements she can individually decide on in a multifaceted transcultural urban space. Situated on the borderland between city and wild outskirt, her house, nevertheless, anchors her in geophysical space of the city meanwhile also emerging as a safe hub for revealing her true identity.

\section{"Being Pregnancy-PurchaseTtracked": the City Diorama of Gender Oppression in Future Home}


Having discussed how Minneapolis is represented in the novel, the final section of this paper addresses the ways in which the distribution of power impacts the construction of the urban space. As the plot unfolds, the topography of the city gradually diversifies into an agglomeration of detention places and hideouts oriented towards women and marked by omnipresent haunting control. Erdrich seems to dramatically illustrate Foucauldian ideas ${ }^{\text {iv }}$ about the mechanism of space distribution applied in disciplinary society by applying it to the urban space of Minneapolis. As Levy (1978) points out, the notion of human control is pivotal to the city space, hence apocalyptic symbolism (p.66). Therefore, in an apocalyptic dystopian novel, the essence of the city will be inevitably marked by signs of control over an individual.

City infrastructure in Erdrich's novel is quicker and easier than other topoi is affected by the mechanisms of oppressive disciplinary power which persecute women. A city is a space where a person can get easily lost and also easily found. On the one hand, it is a conglomeration of strangers, yet on the other hand, the city is a site marked by systematic surveillance. Workplaces, shops, hospitals, common places, even everyday purchased, all of which make use of technology, keep track of every step an individual takes in an urban space. Erdrich clearly illustrates this idea in her novel through the protagonist's experience:

Because I used that old insurance card from the job I had working on the alumni magazine at the University of Minnesota, we will be hard to find. The card has an old box number, no street address. But in the middle of the night, I sit up, eyes wide. I used my credit card to buy baby clothes at Target. I paid my credit card bill online. I slip back down into the tangle of blankets. I am being pregnancy-purchase-tracked by Mother" (Erdrich, 2017, August 20, k.1. 1181).

The city enables all the possible instruments of repressive bio-power: news, radio, TV, social institutes, militant organization and fellow citizens who peep and stalk and can turn on each other in a constant gaze in the Foucauldian sense. Mother [my italics] is a symbolic figure representing continuous oppressive surveillance as well as a new official ideology that is implicitly or explicitly present throughout the urban space of the novel. Various mass media outlets, which serve at this pleasure of the militant regime, continuously broadcast an image of Mother urging women to become "Womb Volunteers" and go to "Future Home Reception Centers." One thousand volunteers are needed to gestate the embryos appropriated from an in-vitro clinic. As a public mouthpiece of the new doctrine, Mother declares embryos to be sacred and women as patriots who must answer the call to save their country in the face of humankind going extinct. Therefore, the city, characterized by tightened morphology and permeated by various systems of communication, becomes a space where meticulous control and ideology spreads expeditiously.

The novel demonstrates how city space may turn into a powerful instrument of biocontrol. When the new regime has installed, the distribution of power in the city changes, which shows itself in imposing new meanings and rules on the space: martial law, much propaganda, remapping of the space. Those who are in power can appropriate space by remapping it through renaming. By renaming the streets of Minneapolis after Bible verses, the new government changes not only the spatial semantics but also the attitude towards people who belong to this place.

"All the street signs were changed overnight. It was a massive project, impressive." <...> "Well, they're Bible verses." "I don't live on Boutwell Street anymore?" "Well, you do according to the U.S. Postal Service. They're still operating under a secular postmaster general. Otherwise, you live on Proverbs 10:7." Wait, I think I know that verse. "The memory 
of the righteous is a blessing, but the name of the wicked will rot?" (Erdrich, 2017, September 5,k.l. 1633)

While Proverb 10:7 suggests for those who are docile and easy to control everlasting remembrance, it promises oblivion for the ones who are determined to resist. By doing so, the regime attempts to erase the memory of the noncompliant from the place and the rights of those to the place. Besides, as far as the regime is highly religious, it strives to mark the space with the visible signs that translate the dominant Christian ideology. In Erdrich's novel, it is through spatial politics that the authoritarian regime works to hold geopolitical power over space concomitantly destroying the personal sense of belonging, which is one of the main pillars of one's sense of self. Furthermore, Erdrich portrays how disciplinary society controls individuals by attaching them to a strictlydefined place, complete with its label, thus predisposing spatial distribution.

The overall and systematic restrictions established in the city impacts various spaces, which, as a result, have modified meaning and functions. A vivid example of such change is the protagonist's house that gradually changes its semantics and converts from a perfectly safe hub and hiding place into a symbolic prison for a pregnant female. In a dystopian manner, the city becomes an agglomeration of such immured loci: prisons, hospitals, hotels, and private houses that turn into "heterotopias $\mathrm{v}$ " or places of "disciplinary monotony," exclusively connected with females who are able to procreate. Oppression and social control, both of which Erdrich depicts in her dystopian novel, are possible only when the individuals (see women) are removed in space into some enclosed places. The prisons and hospitals are for women to "be sequestered and give birth under controlled circumstances." Therefore, some kinds of heterotopias are capable of confining and isolating females in order to control their bodies, and such places gradually fill the urban space of Erdrich's dystopian novel. Multiple Birthing Centres, as well as other similar institutions, bear the characteristics of two kinds of Foucauldian heterotopias, as they appear to be on the border of heterotopia of crises and heterotopia of deviation. The pregnancy as a transition period infers some sort of crises, especially in a society where giving birth becomes rare and problematic, while it also requires society to seek out and ultimately control by detention those deviant individuals who can bear and give birth to a human being.

While limited up to 9 months of pregnancy and thus highly temporal, they have their flow of time, which drags in comparison to the fragmentary chronology of the city outside. As previously mentioned, the main feature of detention places is that they are detached from the outside. Guarded in the same way as the most severe deviation sites, like Psych Wards or Correctional Facilities, which detention place were actually converted from, their "windows are actually double thick with a sandwich of extremely fine wire running diamond-patterned in between" and "the doors upon doors" are locked; hence, the detention places in Erdrich's novel aim to isolate women. Thus, they cannot be seen as a part of common city space but rather a space in itself, thoroughly protected from the outside in an effort to control those who belong there (namely pregnant women) while excluding any outsiders from having access to such a tremendous political resource as "the future of the humankind".

The main characteristic of Erdrich's heterotopias is the gender-based seclusion aimed at control exclusively over female bodies. While the male population is free from any controlled practices oriented towards fertility and childbirth, women of all ages, races, and cultures become hostages to a society of control.

The women in the photographs are alert, smiling, hopeful, perfectly made up. Thanks to Miguel. There are women of every color and age, many younger than me, others older, some wear hats, headscarves, or a hijab, some wear a glittery barret, even an old-school 
scrunchie. $<$...>And below that a line that says: She served the future"(Erdrich, 2017, December 4, k.1. 4036).

Treated as sacred martyrs and portrayed with a glow around their heads and hung on the wall of a Birthing Center, the women emerge as signs of female self-sacrifice, whose bodies are turned into objects while they are deprived of agency. They morph effectively into operating devices, which fulfill the function of reproduction. Thus this city, due to its higher susceptibility together with its female inhabitants, falls victim to an oppressive regime.

\section{Conclusion}

Throughout this investigation, the aim was to examine the urban panorama in Louise Erdrich's dystopian novel Future Home of the Living God. Even though indigenous people have inhabited urban areas since the times immemorial and now their number substantially exceeds those living in other areas, they are rarely associated with the city. Native Americans are assumed to either dissolve in the city or be desperately rejected by the space itself. One of the principal sources which nourish anachronic stereotypes in American popular culture is the paucity of both authentic representations of contemporary Native Americans, both urban and living on reservations and Indigenous peoples of the future.

Urban Indian writing such as Erdrich's Future Home of the Living God is capable of breaking this vicious circle. Although fictional, it is a type of faithful representation as it transfers the frame of reference into the city, thus, rewriting indigenous space. Despite apocalyptic symbolism, Erdrich's novel does not display urban space as alien to a Native American; on the contrary, the novel depicts the city as a space of belonging. The research has shown that one of the essential means of preserving Native cultures and identities in city space is a community, a lack of which may stimulate the emergence of manifold simulacrums. The novel has also raised important questions about the impact of transculturation as a mechanism of preserving the Native identity and cultural survival in cities, which are substantial contact zones fortified by globalization processes.

The most obvious finding to emerge from this study is that the image of the city in this novel follows ambivalent patterns which partially accords with the previous studies. On the one hand, positive urban imagery, acceptance of the city nature and dispositions by the protagonist as well as her attachment to her place in the city all manifest her affection and indisputable belonging. On the other hand, the image of the city in the novel displays its high susceptibility to controlling systems along with the symbolic touch of an impending apocalypse, both so characteristic of dystopian fiction. This dystopian feminist novel demonstrates how rapidly and effectively mechanisms of discipline bio-power can be applied to city infrastructure and dynamics. However, from the indigenous and female perspective, Louise Erdrich, in her constructive feminist and ecologist manner does not blame the topos of the city, but rather depicts it as a victim of humankind and raises alerts to gender-biased oppression, control of reproductivity, and damaging the Earth's ecosystem.

The Native American female author demonstrates that modern indigenous people see the city as their home space while also assessing urban dynamics in global contexts. Inspired and guided by indigenous ways of being and concerns, Erdrich displays various "what ifs" and warns against the fallacies of western epistemology, which is at the core of many urban spaces: separation of spiritual and human, nature and culture; anthropocentric and patriarchal dominant positions 
which see nature and female as inferior. In conclusion, it would appear that, Future Home of the Living God as an indigenous futuristic urban eco-feminist dystopia is a projection of modern urban and global challenges into the nearest future. Informed by indigenous awareness, it displays that everything in the world is interconnected and that the maltreatment of any element in the global bio-cultural system may lead to systematic failures, which may either leave future generations homeless or Earth childless.

\section{Endnotes}

'The term "a contact zone" was coined M.L. Pratt. She defines it as "social spaces where cultures meet, clash, and grapple with each other, often in contexts of highly asymmetrical relations of power, such as colonialism, slavery, or their aftermaths as they are lived out in many parts of the world today" ( 1991, p.33). Although modern urban space may seem to level to a certain extent the former asymmetry of power, the frequency and density of contacts constantly induce cultures to negotiate one's place and identity across various borders in complex and still inequitable interactions

ii As Future Homeof the Living God is written as a diary, all subsequent references to the novel will cite a chapter in the book as a dairy entry with kindle location (k.l.) identified.

iii In his seminal book Manifest manners, Gerald Vizenor adopted Baudrillard's notion of simulacra to point out that the image of the Indian in the culture of dominance often lacks the referent. The Indian as a simulation is "the absence of the tribal real" (1999), which falsifies Native presence and mean the absence of the authentic indigenous cultures instead.

iv Michel Foucault (1977) in Discipline And Punish: the Birth of the Prison admits the significant role of space and spatial distribution techniques in the implementation of power. His perspective is widely applied in this section.

"In an article entitled "Of other places," Foucault defines heterotopias as a locus "outside of all places" as it becomes enclosed in itself and although having a real location, it is separated from other sites (24). In his book, Discipline and Punish, he admits "Discipline sometimes requires an enclosure, the specification of a place heterogeneous to all others and closed in upon itself. It is the protected place of disciplinary monotony" (141).

\section{References}

Deloria, V. (1993). God is red: a native view of religion. New York: Delta.

Erdrich, L. (1985, July 28). Where I Ought to Be: A Writer's Sense of Place. New York Times. Retrieved from www.nytimes.com/1985/o7/28/books/where-i-ought-to-be-a-writer-s-sense-ofplace.html.

Erdrich, L. (2005). Four souls: a novel.[e-book]. Retrieved from https://ifarus.com/four-souls-louise-erdrich

Erdrich, L. (2012). The antelope wife: a novel. New York: Harper Perennial.

Erdrich, L. (2017). Future home of the living god: a novel. HarperCollins [Kindle Edition]. Retrieved from Amazon.com 
Farca, P. A. (2011). Identity in place: contemporary indigenous fiction by women writers in the United States, Canada, Australia, and New Zealand. New York: Peter Lang.

Forbes,J.D. (2001). The Urban Tradition among Native Americans. In S.Lobo, \& K. Peters (Ed.). American Indians and the urban experience (pp. 5-27). Walnut Creek, CA: Altamira Press.

Foucault, M., \& Miskowiec, J. (1986). Of Other Spaces. Diacritics, 16(1), 22-27. Retrieved from JSTOR, www.jstor.org/stable/464648.

Foucault, M. (1977). Discipline and punish the birth of the prison.( A.Sheridan, Trans.). NY: Pantheon Books.

Furlan, L. M. (2017). Indigenous cities: Urban Indian fiction and the histories of relocation. Lincoln: University of Nebraska Press.

Gamber, J. B. (2012). Ridding the World of Waste. Louise Erdrich's The Antelope Wife. In Poswestern horizons: positive pollutions and cultural toxins: waste and contamination in contemporary us ethnic literatures (pp.91-120). Lincoln: University of Nebraska Press.

Garroutte, E. M. (2003). Real Indians: Identity and the survival of Native America. Berkeley, Calif: Univ. of California Press.

Goeman, M. (2013). Mark my words: Native Women mapping our nations (First Peoples: New directions in indigenous studies). University of Minnesota Press.

Levy, D. (1978). City Signs: Toward a Definition of Urban Literature. Modern Fiction Studies, 24(1), 6573. Retrieved from http://www.jstor.org/stable/26281973

Lyubymova, S. (2019). Stereotyping Indigeneity: the Case of Native American. Rupkatha Journal on Interdisciplinary Studies in Humanities, 11(2), 1-19. doi: https://dx.doi.org/10.21659/rupkatha.viın2.05

Medak-Saltzman, D. (2017). Coming to You from the Indigenous Future: Native Women, Speculative Film Shorts, and the Art of the Possible. Studies in American Indian literatures, 29(1), pp. 139-171. doi: 10.5250/studamerindilite.29.1.0139.

Miller, C. (2001). Telling the Indian Urban. Representation in American Indian fiction. In S.Lobo, \& K.Peters (Ed.). American Indians and the urban experience (pp. 29-47). $\quad$ Walnut Creek, CA: Altamira Press.

Noodin, M. (2014). Bawaajimo: A dialect of dreams in Anishinaabe language and literature. East Lansing: Michigan State University Press.

Lobo, S., \& Peters, K. (2001). American Indians and the urban experience. Walnut Creek, CA: Altamira Press.

Philp, K. (1985). Stride Toward Freedom: The Relocation of Indians to Cities, 1952- 1960. The Western Historical Quarterly, 16(2), 175-190. doi:10.2307/96966o

Pratt, M. (1991). Arts of the Contact Zone. Profession, 33-40. Retrieved from http://www.jstor.org/stable/25595469

Vizenor, G. R. (1999). Manifest manners: Postindian warriors of survivance. Lincoln (NE: University of Nebraska Press.

United States Census Bureau.(2010). The American Indian and Alaska Native Population: 2010. Retrieved from www.census.gov/history/pdf/c2o1obr-10.pdf.

Walters, K.L. (1999). Urban American Indian Identity Attitudes and Acculturation Styles. Journal of human behavior in the social environment, 2 (1-2), pp. 163-178. doi: 10.1300/j137vo2no1_11 
Wolfe, P. (2011). After the Frontier: Separation and Absorption in US Indian Policy. Settler colonial studies, 1 (1), pp. 13-51. doi:10.1080/2201473X.2011.106488

Wolfe, P. (2006). Settler Colonialism and the Elimination of the Native. Journal of genocide research, 8(4), pp. 378-409. doi:10.1080/14623520601056240

Whyte, K.P. (2018). Indigenous Science (fiction) for the Anthropocene: Ancestral Dystopias and Fantasies of Climate Change Crises. Environment and planning : Nature and $\quad$ space, 1(1-2), pp. 224-242. doi:10.1177/2514848618777621

Svitlana Kot is a PhD. Student at Petro Mohyla Black Sea National University, Mykolaiv, Ukraine. Her primary area of expertise is American Literature and Space Theories. Her current research project focuses on the Poetics of Space in the novels by Louise Erdrich, a Native American writer, approached through the transcultural lens. She is also a member of the research group "The Bio-Politics of Borders in Times of Crisis" within the cooperation between the University of Saarland, Germany, and Petro Mohyla Black Sea National University, Ukraine. 